\title{
Time of the sidereal year affects responsiveness to the phase-resetting effects of photoperiod in the ewe*
}

\author{
G. L. Jackson $\dagger$, H. T. Jansen $\dagger$, D. E. Kuehl† and R. D. Shanks $\ddagger$ \\ Departments of $\dagger$ Veterinary Biosciences and $\ddagger$ Animal Sciences, University of Illinois, Urbana, \\ Illinois 61801 , U.S.A.
}

\begin{abstract}
Summary. Two groups of ovary-intact ewes were placed in separate photochambers on the day of the vernal equinox (VE). One group was exposed to a $16 \mathrm{~h}$ light: $8 \mathrm{~h}$ dark (16L:8D) photoperiod and the other to $8 \mathrm{~L}: 16 \mathrm{D}$. On the day of the summer solstice (SS) and at 90-91-day intervals thereafter [autumnal equinox (AE), winter solstice (WS), VE and SS], each group was changed to the opposite photoperiod. The latent period between each change and either onset or cessation of cycles, as determined by measuring blood progesterone concentrations, was recorded. The latent period between change to $8 \mathrm{~L}: 16 \mathrm{D}$ and onset of cycles was shortest after the exposure at $\mathrm{AE}$ and longest after exposure at WS $(P<0.001)$. The latent period after AE was shorter $(P<0.001)$ than after VE. The correlations were small between ambient temperature and interval to onset of cycles. The latent period to cessation of cycles in response to 16L:8D was shorter after SS exposure than after WS exposure $(P<0 \cdot 01)$, but other differences were not significant. There was a strong $(r=-0.94, P<0.05)$ negative correlation between interval to cessation of cycles and ambient temperature. Cessation of cycles in response to $16 \mathrm{~L}: 8 \mathrm{D}$ occurred more rapidly $(P<0.001)$ than onset in response to $8 \mathrm{~L}: 16 \mathrm{D}$. These results show that responsiveness to the inductive effects of photoperiod varies significantly with time of the sidereal year.
\end{abstract}

Keywords: sheep; seasonal breeding; photoperiod; circannual rhythm; progesterone

\section{Introduction}

Sheep, like numerous other species, exhibit cycles of breeding activity with periods of 1 year, i.e. have annual breeding seasons. The ability of changes in photoperiod length to induce or suppress reproductive activity is well established (see review by Karsch et al., 1984).

The effectiveness of changes in photoperiod length is affected by photorefractoriness. Rams and ewes exposed to continuous short-day photoperiods starting near or at the winter solstice fail to maintain increased gonadotrophin secretion (Lincoln, 1980; Worthy \& Haresign, 1983; Robinson et al., 1985), whereas rams and ewes exposed to short-day photoperiods in April or early August respond with increased gonadotrophin secretion and reproductive activity (Yeates, 1949; Lincoln, 1980). Ewes exposed continuously to long-day photoperiods starting at the summer solstice fail to show a decrease in $\mathrm{LH}$ secretion or start to cycle at the same time as ewes held outdoors (Robinson \& Karsch, 1984; Jackson et al., 1988). These failures to respond to inductive or suppressive photoperiods are partly attributable to photorefractoriness resulting from previous exposure of the animal to the same or similar photoperiod. However, the lack of response also may be partly attributable to an endogenous rhythm of photosensitivity. That is, there may be rhythmic

\footnotetext{
${ }^{*}$ Reprint requests to Dr G. L. Jackson, College of Veterinary Medicine, 2001 South Lincoln, Urbana, IL 61801,
} U.S.A. 
endogenous changes in sensitivity or responsiveness to inductive or suppressive photoperiods (Saunders, 1977).

Evidence for an endogenous rhythm or change of sensitivity may be provided by an experiment designed for other purposes. Mauléon \& Rougeot (1962) kept 4 breeds of ewes in a photoregimen in which 90 days exposure to increasing daily photoperiod from 8 -h light $(8 \mathrm{~L})$ to $16-\mathrm{h}$ light $(16 \mathrm{~L})$ was regularly alternated with 90 days of decreasing daily photoperiod from 16L to $8 \mathrm{~L}$ for $3-4$ years. The results showed that Préalpes ewes exposed to decreasing photoperiod at the time of autumnal equinox responded with onset of oestrous cycles significantly sooner than did ewes exposed to decreasing photoperiod at the time of the vernal equinox. There are many other studies in which sheep were alternately exposed to long and short photoperiods; however, systematic evaluation of the response latency as a function of time of the sidereal year has not been reported. Legan \& Karsch (1980) evaluated latency of responses by ewes to a series of changes between $8 \mathrm{~L}: 16 \mathrm{D}$ and 16D:8L photoperiods, but the results were confounded by the fact that some groups were exposed to 120 days of treatment, whereas others were exposed to only 90 days before a change was made. Examination of the results of these earlier studies prompted us to design an experimental regimen which equalized the effects of photorefractoriness and allowed us to examine systematically the responsiveness of the hypothalamo-hypophysial-gonadal system of ewes confined to photochambers to long- or short-day photoperiods applied at different times of the sidereal year. The observation of differential responsiveness to a given photoregimen at different times of the sidereal year would be consistent with the hypothesis of an endogenous rhythm to the phase-resetting effects of that photoperiod.

\section{Materials and Methods}

General. These studies were conducted from March 1986 to December 1987 on mature ewes that were either pure Suffolk or predominantly of the Suffolk breed. All animals were kept at the Veterinary Research Farm, Urbana, Illinois $\left(40^{\circ} \mathrm{N}\right)$ where they were maintained either outdoors or in rooms (photochambers) under artificial photoperiods. Light in each photochamber was provided by four 40-W fluorescent bulbs that supplied an intensity of $\cong 350$ lux in the centre of the room at the height of the sheep's head. Ambient temperature in the rooms was partly controlled by air-conditioners and electric heaters. Temperatures were monitored with 'maximum-minimum' thermometers and recorded thrice weekly. The ewes were fed dried alfalfa hay and a grain supplement.

Experimental design. Two groups of 7 ewes each were placed into separate photochambers on the day of the vernal equinox (2l March). Group A initially was exposed to a photoperiod of 16-h light:8-h dark (16L:8D) for 90 days. Group B initially was exposed to a photoperiod of $8 \mathrm{~L}: 16 \mathrm{D}$ for 90 days. The animals then were exposed to alternating $90-91$-day cycles of $16 \mathrm{~L}: 8 \mathrm{D}$ or $8 \mathrm{~L}: 16 \mathrm{D}$. With this regimen the 2 groups were $180^{\circ}$ out of phase with respect to each other in terms of exposure to the photoperiods (Fig. 1). This regimen resulted in exposure of the ewes to $8 \mathrm{~L}: 16 \mathrm{D}$ or 16L:8D for approximately 90-day periods starting at the vernal and autumnal equinoxes (VE and AE), and at the summer and winter solstices (SS and WS). Since the ewes were exposed to the opposite photoperiod for constant intervals before the test exposures the responses were not affected by different levels of refractoriness to the test photoperiod. Blood samples were taken thrice weekly by puncture of the jugular vein for the duration of the experiment. These samples were assayed for progesterone concentrations to monitor the occurrence of ovarian cycles.

Hormone assay. Blood samples were placed in heparinized tubes, stored in a refrigerator or on ice, and centrifuged at $\cong 4^{\circ} \mathrm{C}$ within $2 \mathrm{~h}$ of collection. Plasma was collected and stored at $-20^{\circ} \mathrm{C}$ until assayed. A validated 'rapid assay' procedure, which did not require extraction of plasma, was used to assay progesterone. All operations were done in a single glass scintillation mini-vial. To this vial the following materials were added: plasma ( $200 \mu \mathrm{l}), 2 \cdot 5 \%$ bovine serum albumin (BSA) in phosphate-buffered saline (PBS) $(300 \mu \mathrm{l}),\left[{ }^{3} \mathrm{H}\right]$ progesterone (sp. act. $110 \mathrm{Ci} / \mathrm{mmol}: \cong 10000 \mathrm{c} . \mathrm{p} . \mathrm{m}$. in $100 \mu \mathrm{l} 2.5 \%$ BSA-PBS) and $100 \mu \mathrm{l}$ antiprogesterone (Sherwood et al., 1980) previously diluted 1:1200 in 1:100 normal rabbit serum-0.05 M-EDTA-PBS. This mixture which contained antiprogesterone at a dilution of 1:7200 was gently mixed for $\cong 10 \mathrm{sec}$ on a Vortex mixer and allowed to incubate at room temperature for $4 \mathrm{~h}$. Then $100 \mu \mathrm{l}$ of previously titrated anti-rabbit gamma globulin were added and the solution again mixed and incubated at room temperature for about $15 \mathrm{~h}$. The vials were then cooled in a refrigerator $\left(4^{\circ} \mathrm{C}\right)$ for $2-4 \mathrm{~h}$. Cold $\left(4^{\circ} \mathrm{C}\right)$ PBS $(4 \mathrm{ml})$ was added to each vial. The vials were centrifuged at $1200 \mathrm{~g}$ for $30 \mathrm{~min}$ at $4^{\circ} \mathrm{C}$. The supernatant was poured off and discarded. The vial was inverted and drained for $15 \mathrm{~min}$. Then $5.5 \mathrm{ml}$ ACS scintillation fluid (Amersham) were added and the vials were counted in a liquid scintillation counter.

Validation procedures included determining the 'recovery' of 50 to $750 \mathrm{pg}$ of added unlabelled progesterone from plasma samples of ovariectomized ewes, determination of parallelism between plasma samples and the standard curve, and correlation of plasma progesterone concentrations obtained with this assay and our standard 'extraction' 


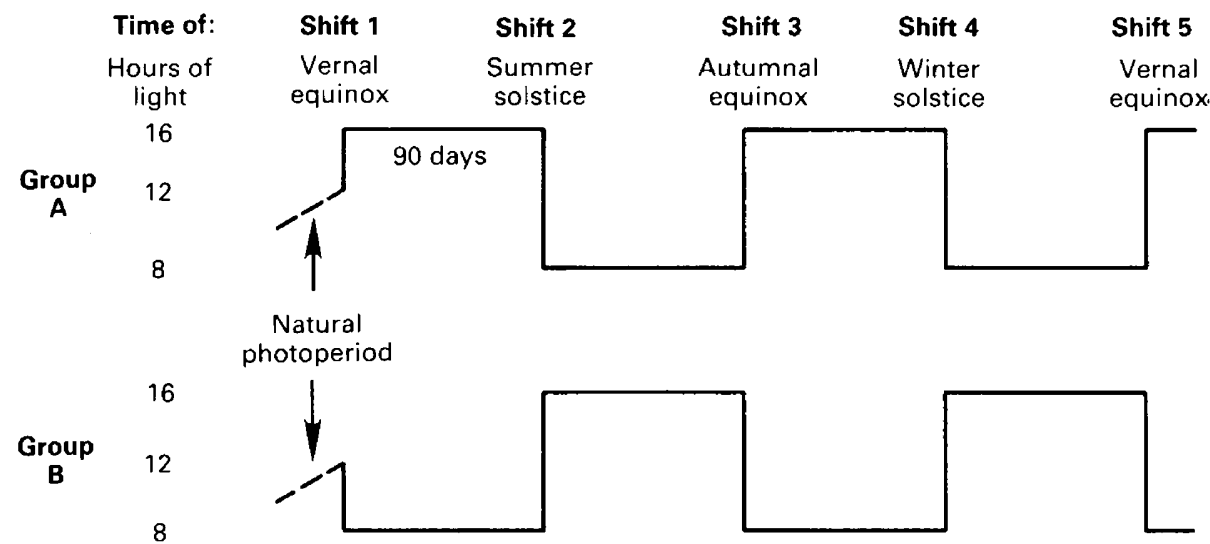

Fig. 1. Schematic representation of the protocol for exposure of ewes in Groups A and B to alternating periods of $16 \mathrm{~L}: 8 \mathrm{D}$ and $8 \mathrm{~L}: 16 \mathrm{D}$ photoperiods. Photoperiods were changed at the time of the vernal and autumnal equinox and the winter and summer solstice.

assay (Pau et al., 1982). Sequential samples of plasma from 6 cyclic ewes and a series of ovariectomized and anoestrous ewes were used in this last procedure.

Recovery of unlabelled progesterone averaged $87 \pm 6 \%$ and was proportional to the amount added to the plasma. Inhibition curves of different volumes of plasma containing variable amounts of progesterone were parallel to the standard curve. The correlation between values of progesterone measured in this assay and our standard 'extraction' assay varied from 0.92 to 0.97 . Profiles of changes in progesterone concentration during the oestrous cycles of all 6 ewes were nearly identical in the 2 assays. The sensitivity of this assay was approximately $50 \mathrm{pg} /$ tube and the intraand inter-assay coefficients of variation were $10.6 \%$ and $11.2 \%$, respectively. By these criteria, we judge that this rapid assay is fully valid for monitoring oestrous cycles. Because of a relatively high background, it probably will not be useful for determining small fluctuations of progesterone under certain other experimental conditions.

Statistical analysis. To aid in statistical analysis, the day on which each shift of photoperiod occurred was designated as Day 0. The end-point analysed was the interval in days (latent period) between 2 events (e.g. start of a specific regimen and cessation or onset of oestrous cycles). To assist in determining when cycles started or ceased, progesterone profiles for each ewe were graphed. Each cycle was defined by the appearance of a profile of at least 4 sequential progesterone values above background with a peak value exceeding $1 \mathrm{ng} / \mathrm{ml}$. In all cases these profiles were unambiguous as peak concentrations usually exceeded $3 \mathrm{ng} / \mathrm{ml}$. Those cases in which only 1 or 2 contiguous progesterone values fell between background and $1 \mathrm{ng} / \mathrm{ml}$ were considered short luteal phases. Onset of cycles was defined as the first day of the first full cycle of a series. Similarly, cessation was defined as the last day of the last cycle of a series.

The latent period to onset of cycles was measured during exposure to $8 \mathrm{~L}: 16 \mathrm{D}$ while the latent period to cessation of cycles was measured during exposure to $16 \mathrm{~L}: 8 \mathrm{D}$. The responses to each photoregimen were analysed as independent experiments although we recognized the potential association between responses because the same ewes were evaluated under both light regimens. For each variable, comparisons were made between equinox and solstice (between group), between VE and AE within equinox and between SS and WS within solstice (between treatment within group). One way analysis of variance was performed with the aid of the statistical program of SAS Institute Inc. The level of significance was set at $P<0.05$.

Also, for each variable, the mean latent period within a photoregimen at a given time of year was correlated with both the mean maximum and mean minimum ambient temperatures which occurred in each photochamber during that exposure period. First, the mean latent period of response to a given photoregimen applied at a given time, i.e. response to $16 \mathrm{~L}: 8 \mathrm{D}$ at VE, was calculated. 'Maximum-minimum' thermometers were used to monitor photochamber temperature. Thrice weekly, the maximum and minimum temperatures were recorded and the thermometers reset. From these data, the means of maximum and minimum ambient temperatures during the interval from onset of treatment to the mean latent period were calculated. Finally, separate correlation coefficients between latent periods and mean maximum and minimum ambient temperatures were calculated with the aid of a SAS Institute Inc. program.

\section{Results}

\section{Latent periods}

Results of responses to the first period of exposure to controlled photoperiod were not included in the analysis since prior exposure to the natural photoperiod had conditioned the animals. As 
expected, the 7 ewes exposed to $16 \mathrm{~L}: 8 \mathrm{D}$ at the vernal equinox remained in anoestrus. Unexpectedly, 5 of the 7 exposed to $8 \mathrm{~L}: 16 \mathrm{D}$ also were still in anoestrus at the summer solstice. They clearly had not received sufficient exposure to naturally increasing long days to resensitize them to the inductive effects of short days. Since these ewes were in anoestrus at the summer solstice, they could not meaningfully be tested for interval to cessation of cycles in response to $16 \mathrm{~L}: 8 \mathrm{D}$ during the next subsequent exposure period, and those data also were discarded. To compensate for this, the length of the total experiment was then extended to 640 days.

The results are summarized in Fig. 2. The interval between onset of $16 \mathrm{~L}: 8 \mathrm{D}$ and cessation of cycles (latent period) was significantly greater $(P<0.01)$ when exposure was started at winter solstice than when it was started at the summer solstice. Comparisons for cessation of cycles between equinoxes and between equinox and solstice were not significantly different.

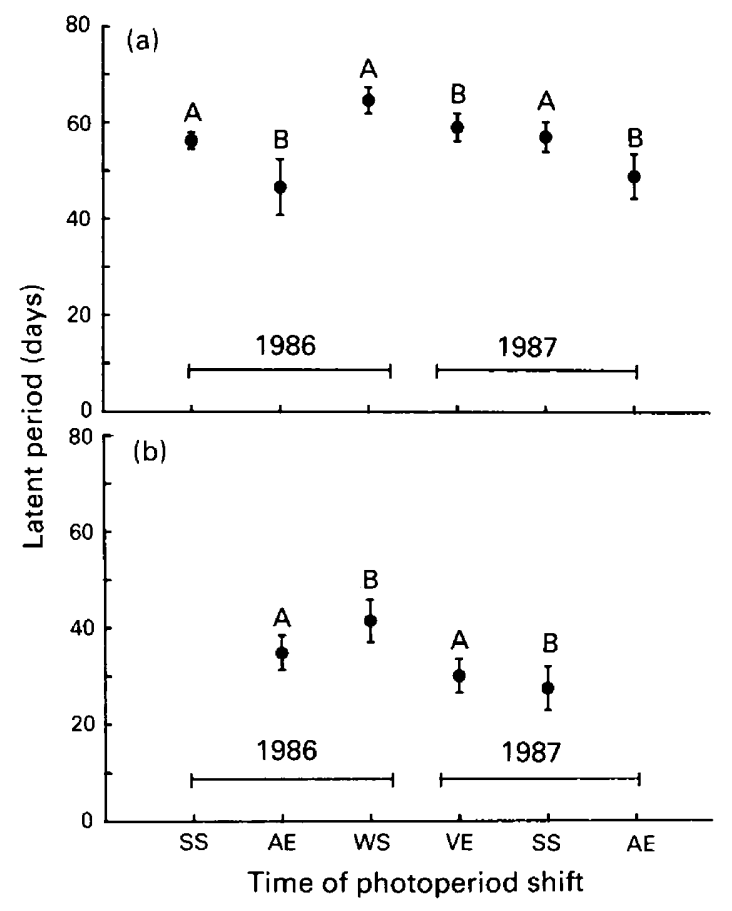

Fig. 2. Mean ( \pm s.e.m.) latent periods in days between onset of a 16L:8D photoperiod and cessation of ovarian cycles (b) and onset of an $8 \mathrm{~L}: 16 \mathrm{D}$ photoperiod and onset of ovarian cycles (a) in ewes. Exposure to each photoperiod was started at the summer solstice (SS), autumnal equinox (AE), winter solstice (WS), or vernal equinox (VE). The A and $B$ above each datum point indicate the treatment group from which those data were obtained.

There was a significant effect of season of exposure to $8 \mathrm{~L}: 16 \mathrm{D}$ on the latent period to onset of cycles. The most rapid response was to the autumnal equinox exposure which was significantly more rapid $(P<0.001)$ than the response to the vernal equinox exposure. Onset of cycles in response to the winter solstice exposure was significantly slower $(P<0.01)$ than those in response to exposure at the summer solstice or autumnal equinox. The relatively rapid onset of cycles after autumnal equinox exposure was observed in both 1986 and 1987. There was no significant difference in response to autumnal equinox exposure in 1986 and 1987. 


\section{Effects of temperature}

During all periods of exposure ambient temperatures ranged from about 15 to $25^{\circ} \mathrm{C}$. Correlation analysis revealed a strong negative correlation $(P=0.05)$ between both mean maximum (Fig. 3) and minimum ambient temperatures and the latent periods to $16 \mathrm{~L}: 8 \mathrm{D}(r=-0.96$ and $r=-0.94$, respectively). In contrast, the correlations between mean maximum and minimum ambient temperatures and latent periods to $8 \mathrm{~L}: 16 \mathrm{D}$ were of the opposite sign and near zero ( $r=0.005$ and $r=0.001$, respectively).

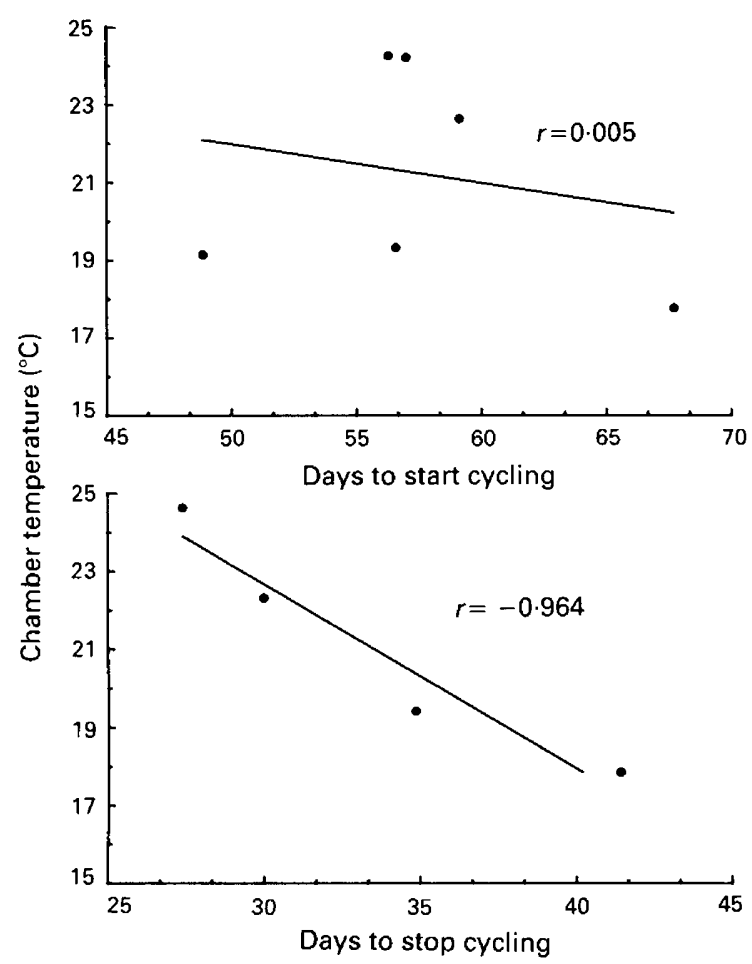

Fig. 3. Relationship between mean maximum ambient temperature in photochambers and latent periods to cessation of ovarian cycles in response to a $16 \mathrm{~L}: 8 \mathrm{D}$ photoperiod (lower panel) or to onset of ovarian cycles in response to a $8 \mathrm{~L}: 16 \mathrm{D}$ photoperiod (upper panel). The correlation coefficients are indicated in the upper right of each panel.

\section{Response to $16 L: 8 D$ and $8 L: 16 D$}

The mean interval between onset of exposures to $16 \mathrm{~L}: 8 \mathrm{D}$ and cessation of oestrous cycles (33.4 \pm 1.8 days) was significantly less $(P<0.001)$ than the mean interval between onset of $8 \mathrm{~L}: 16 \mathrm{D}$ and onset of cycles $(57 \cdot 1 \pm 1.5$ days). In many cases, ewes had only one cycle after exposure to the $16 \mathrm{~L}: 8 \mathrm{D}$ photoperiod.

\section{Discussion}

The inductive effects of $8 \mathrm{~L}: 16 \mathrm{D}$ were most rapid when applied at the time of the autumnal equinox and slowest when applied at the winter solstice. This response showed little correlation with 
ambient temperature. Duration of prior exposure to $16 \mathrm{~L}: 8 \mathrm{D}$ was equal in all cases, and so the effect of time of year could not have been due to differential degrees of photorefractoriness. This time of year effect apparently represents either an endogenous change in responsiveness to the $8 \mathrm{~L}: 16 \mathrm{D}$ photoperiod or the influence of unknown environmental factors. It seems unlikely that variation in dietary factors played a role, since dried hay subjected to several months of storage was fed throughout the study. However, such an effect cannot be ruled out. Our results agree with those of Mauléon \& Rougeot (1962) and the observation of greatest responsiveness at the autumnal equinox in two successive years is consistent with the hypothesis of a rhythm of sensitivity; however, these data are not sufficient to prove an endogenous rhythm.

Response intervals to shifts from $8 \mathrm{~L}: 16 \mathrm{D}$ to $16 \mathrm{~L}: 8 \mathrm{D}$ were significantly negatively correlated with ambient temperatures, and so it is difficult to reach a conclusion regarding the basis of changes in responsiveness to $16 \mathrm{~L}: 8 \mathrm{D}$. Legan \& Karsch (1980) found a similar correlation between temperature and responsiveness to $16 \mathrm{~L}: 8 \mathrm{D}$. Although their findings were based on a compilation of results from two series of studies, the overall results were very similar to ours. In a subsequent paper, Robinson \& Karsch (1984) suggested that these results could equally well have been due to variable effects of photorefractoriness (some of their ewes previously had been exposed to 120 days of $8 \mathrm{~L}: 16 \mathrm{D}$ and others to 90 days of $8 \mathrm{~L}: 16 \mathrm{D}$ before being exposed to the $16 \mathrm{~L}: 8 \mathrm{D}$ photoperiod). This, however, was not a factor in our study. The consistency of results from the two studies strongly suggests an effect of temperature.

In summary, our results clearly show that time of the sidereal year at which ewes confined to photochambers are exposed to an inductive photoperiod regimen significantly affects the rate of response to that regimen. While these results could be interpreted as support for an endogenous rhythm of responsiveness to the phase resetting effects of an inductive photoregimen, the effects of other unknown environmental factors cannot be ruled out. The absolute range of response intervals to the inductive photoregimen, while highly significant, was small, i.e. only about one oestrous cycle length. Although there may be an endogenous rhythm of sensitivity to the phase resetting effects of photoperiod, it is not very robust. Finally, our results are consistent with previous observations which suggest that a primary factor affecting responsiveness to an inductive photoregimen is the degree of photorefractoriness or 'photoperiod history' of the ewe at the time it is placed on an inductive regimen (e.g. Robinson \& Karsch, 1984).

We thank Dr O. D. Sherwood for the gift of antiprogesterone serum. This work was supported by NIH grant HD 13037.

\section{References}

Jackson, G.L., Gibson, M. \& Kuehl, D. (1988) Photoperiodic disruption of photorefractoriness in the ewe. Biol. Reprod. 38, 127-134.

Karsch, F.J., Bittman, E.L., Foster, D.L., Goodman, R.L., Legan, S.J. \& Robinson, J.E. (1984) Neuroendocrine basis of seasonal reproduction. Recent Prog. Horm. Res. 40, 185-232.

Legan, S.J. \& Karsch, F.J. (1980) Photoperiodic control of seasonal breeding in ewes: modulation of the negative feedback action of estradiol. Biol. Reprod. 23, 1061-1068.

Lincoln, G.A. (1980) Photoperiodic control of seasonal breeding in rams-the significance of short-day refractoriness. In Endocrinology, pp. 283-286. Eds J. W. Funder \& F. A. O. Mendelsohn. Australian Academy of Sciences, Canberra.
Mauléon, P. \& Rougeot, J. (1962) Régulation des saisons sexuelles chez des brebis de races différentes au moyen de divers rhythmes lumineux. Annls Biol. anim. Biochim. Biophys. 2, 209-222.

Pau, K.Y., Kuehl, D.E. \& Jackson, G.L. (1982) Effect of frontal hypothalamic deafferentation on luteinizing hormone secretion and seasonal breeding in the ewe. Biol. Reprod. 27, 999-1009.

Robinson, J.E. \& Karsch, F.J. (1984) Refractoriness to inductive day length terminates the breeding season of the Suffolk ewe. Biol. Reprod. 31, 656-663.

Robinson, J.E., Wayne, N.L. \& Karsch, F.J. (1985) Refractoriness to inhibitory day length initiates the breeding season of the Suffolk ewe. Biol. Reprod. 32, $1024-1030$. 
Saunders, D.S. (1977) An Introduction to Biological Rhythms. Blackie, Glasgow.

Sherwood, O.D., Crnekovic, V.E., Gordon, W.L. \& Rutherford, J.E. (1980) Radioimmunoassay of relaxin throughout pregnancy in the rat. Endocrinology 107 , $691-698$.

Worthy, K. \& Haresign, W. (1983) Evidence that the onset of seasonal anoestrus in the ewe may be inde- pendent of increasing prolactin concentrations and day length. J. Reprod. Fert. 69, 41-48.

Yeates, N.T.M. (1949) The breeding season of sheep with particular reference to its modification by artificial means using light. J. agric. Sci., Camb. 39, 1-43.

Received 2 June 1988 